\title{
What information is needed to design anti-seismic structures?
}

\author{
P. Clemente, D. Rinaldis, G. Bongiovanni \& F. Saitta \\ ENEA, Rome, Italy
}

\begin{abstract}
Our knowledge about earthquakes and their effects on structures is still not satisfactory. But what do structural engineers need in order to design antiseismic buildings? As is well known, the first step in any structural design is the analysis of loads and, among these, the seismic input is an important issue. This is defined by means of a basic hazard analysis and the local seismic response. The uncertainties about the local seismic response could be more important than those relating to the basic analysis results. The second step is the structural modeling, where the suitability depends on how good is the description of the material behavior and the structural behavior both in the elastic and inelastic range. Knowledge of these is very important in order to define the behavior factor, which is a measure of the inelastic capacity of the building, i.e., its capacity to dissipate energy. Some recent seismic events in the world have questioned several assumptions of the present design rules, prescribed by the seismic codes. In this paper some issues about the anti-seismic structural design are discussed in order to give some proposals to improve our way of thinking about structural safety against earthquakes.
\end{abstract}

Keywords: structural safety, technical codes, seismic hazard, new anti-seismic technologies.

\section{Introduction}

How good is our knowledge about earthquakes and their effects on structures? When reading modern codes one could have the feeling that the issue of designing anti-seismic structures is well known and almost any problem has been solved but the reality is quite different. 
With reference to seismic actions consider first the 2009 L'Aquila earthquake, Italy $\left(\mathrm{M}_{\mathrm{W}}=6.3\right)[1,2]$. Six accelerometric stations very close to the city recorded, at zero Joyner-Boore distance from the fault, peak ground accelerations ranging from 0.30 to $0.65 \mathrm{~g}$. These exceeded those considered by the Italian code for new ordinary buildings, which refers to the return period $\mathrm{T}_{\mathrm{R}}=475$ years, but were comparable with those relative to $T_{R}=2475$ years. In one site the obtained values were even higher than those associated to $T_{R}=2475$ years [3]. The corresponding response spectra showed the same exceedance with reference to the elastic spectra of the code. Similar occurrences were observed in several other cases, such as during the 2011 Christchurch earthquake, New Zealand $\left(\mathrm{M}_{\mathrm{W}}=6.3\right)$, and the 2011 Tohoku earthquake Japan $\left(\mathrm{M}_{\mathrm{W}}=9.0\right)$ [4]. It is important to underline that seismic hazard classification is mainly based on the seismic history, on the return period concept and on the knowledge of existing faults, capable or not. This approach doesn't account for high magnitude events, whose occurrence has been assessed in prehistoric age. In the deterministic approach, individual earthquake scenarios are developed for each relevant seismic source and paleoseismic sources, if known, are considered. Then a ground motion is selected accounting for the maximum credible earthquake, the distance from the site and its geological characteristics. In the probabilistic approach all the possible and relevant deterministic earthquake scenarios are considered as well as all possible ground motion probability.

Going back to L'Aquila earthquake, another issue arises, which is relative to the observed damage. According to what has been said about the seismic intensity one should expect that most of the structures, built with reference to old codes or without any code, would have collapsed. Why did this not happen? It is apparent that our knowledge about the actual behavior of structures is still not satisfactory.

In this paper some issues about the anti-seismic design are discussed in order to give proposals to improve our way of thinking about the structural safety against earthquakes. As well known a good structural design is based on a detailed load analysis and a suitable modeling of the structure. The first step includes the seismic input, which is very influenced by the local seismic response. The second one cannot disregard the knowledge of the material properties as well as the behavior of the structure, also in the inelastic range. In the structural design this is accounted for by means of the behavior factor, which is a measure of the inelastic capacity of the building, i.e., its capacity to dissipate energy.

\section{Seismic hazard assessment}

Seismic action is completely described by its components along the three orthogonal axes, two horizontal and the vertical. In practical applications, when using linear analysis, the surface response spectrum is sufficient to determine the expected maximum effects on structures. But what are the parameters that define the response spectrum shape and amplitude? Usually, the acceleration elastic response spectrum is given for a rigid soil with horizontal surface and refers to a 
conventional damping ratio $\xi=5 \%$. It assumes the shape in Fig. 1 , which is defined by the horizontal peak ground acceleration (PGA), the maximum amplification $\mathrm{F}$, and the value $\mathrm{T}^{*}$ of the period. The values of PGA, F and $\mathrm{T}^{*}$, evaluated according to the probabilistic seismic hazard assessment (PSHA), are provided for the points of a square grid of side $5.5 \mathrm{~km}$ on the Italian territory as a function of the occurrence probability $\mathrm{P}_{\mathrm{R}}$ in 50 years (this is the minimum service life time usually accepted for a building), which is related to the return period $T_{R}$. So PSHA provides a set of acceleration response spectra, each one relative to a return period in the range up to 2475 years, which corresponds to lowest value of occurrence probability $\mathrm{P}_{\mathrm{R}}=2 \%$. This limit is obviously related to our knowledge about the seismic history, which cannot go back in time much.

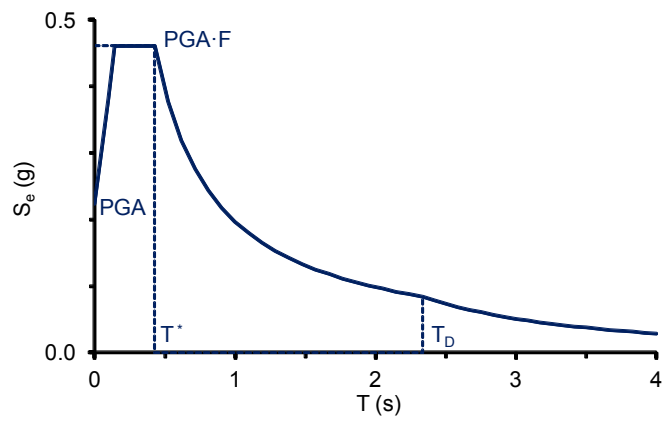

Figure 1: Acceleration response spectrum shape.

Which value of probability shall we consider in the structural design? This is a question for engineers, not for seismologist, because the answer requires the knowledge of how this choice influences the structural design. Actually this choice is done in the technical codes. So, in practice, it is a political choice, on which building and repairing costs depend. Nowadays the occurrence probability $\mathrm{P}_{\mathrm{R}}=10 \%$ in 50 years is accepted for ordinary buildings, which corresponds to $\mathrm{T}_{\mathrm{R}}=475$ years. This should be a conscious choice, which entails a certain risk.

Recent events seemed to suggest considering lower values of probability. In Figure 2 the PGA expected at Mirandola town, Italy, is plotted against $P_{R}$. As one can see the value corresponding to a probability of $10 \%$ is lower than $0.15 \mathrm{~g}$. Actually a higher peak was recorded on soft soil $(\approx 0.30 \mathrm{~g})$ during the 2012 Emilia earthquake, corresponding to PGA $>0.20 \mathrm{~g}$ at the bedrock, which is associated, according to the reference seismic hazard, to a probability $\mathrm{P}_{\mathrm{R}}<5 \%$. This value is very low but it is not zero! As a matter of fact Mirandola is classified as low-medium intensity seismic area. This means that earthquakes do not occur very frequently and with highest intensity, but they can occur. Obviously, to be on the safe side, one should refer to $P_{R}=2 \%\left(T_{R}=2475\right.$ years $)$, which generally gives values closer and sometimes higher than those of the determinist approach. 


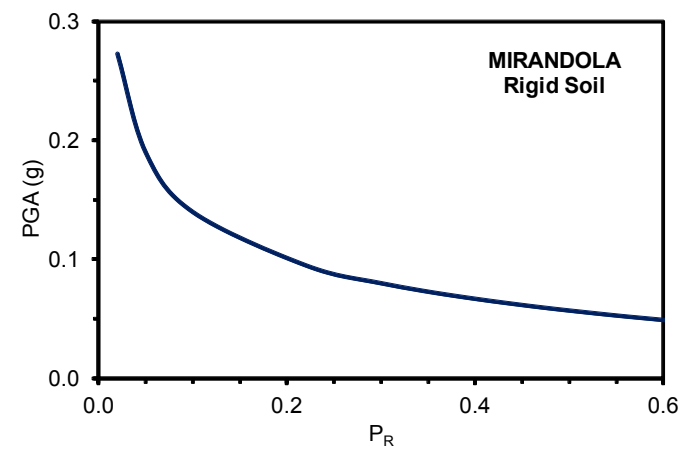

Figure 2: $\quad$ PGA versus $\mathrm{P}_{\mathrm{R}}$ for Mirandola site.

\section{The local effects}

The seismic waves can be amplified due to site effects, which can be accounted for by multiplying PGA, and so the entire spectrum, by a soil coefficient $\mathrm{S}$. This is given in the Italian code as a function of the product PGA $F$, which represents the maximum spectral amplitude for rigid soil (Figure 3), and varies with the occurrence probability $\mathrm{P}_{\mathrm{R}}$ for a fixed site. In more details, $\mathrm{S}$ is always equal to unity for rigid soil. For the other types of soil it varies from its maximum value, corresponding to low values of $\mathrm{PGA} \cdot \mathrm{F}$, to its minimum one at high values of $\mathrm{PGA} \cdot \mathrm{F}$. The ratio between the two extreme values, equal to unity for rigid soil, increases up to 2 for soft soil. As a matter of fact, while the minimum values are similar for all types of soil, the maximum ones are very different. So the amplification of motion due to earthquake assumes a very important role especially for lower values of the maximum spectral amplitude. It is worth reminding that local effects due to slope are also accounted for by means of an amplification coefficient, which ranges from 1.0 to 1.4 .

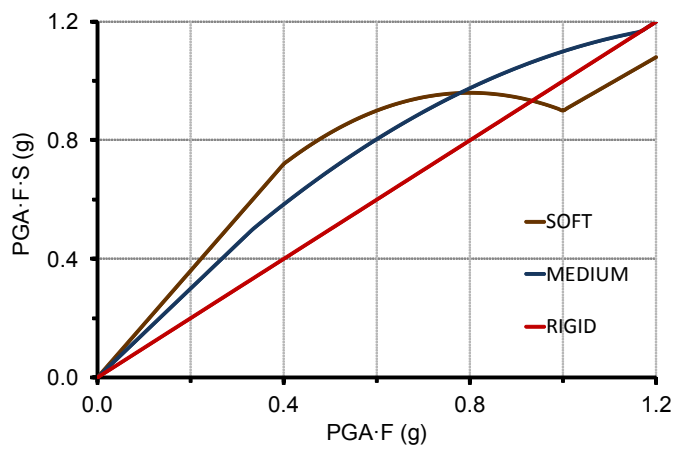

Figure 3: $\quad \mathrm{PGA} \cdot \mathrm{F} \cdot \mathrm{S}$ versus $\mathrm{PGA} \cdot \mathrm{F}$. 
The range of maximum amplification in the acceleration spectrum varies from site to site and depends also on the soil characteristics. The first aspect is usually accounted for by means of the period $\mathrm{T}^{*}$, which separates the range with constant maximum acceleration $\left(T<T^{*}\right)$, from the range with constant velocity $\left(T>T^{*}\right)$ in the spectrum relative to rigid soil (Figure 1). $\mathrm{T}^{*}$ ranges from 0.1 to $0.6 \mathrm{sec}$ in the Italian territory. The range of maximum amplification becomes larger for soft soils. So for other soil types $\mathrm{T}^{*}$ is substituted by $\mathrm{T}_{\mathrm{C}}$, which is derived from $\mathrm{T}^{*}$ by means of simple relationships. In Figure 4 the curves of $T_{C}$ against $T^{*}$ (continuous lines) and those of the ratio $T_{C} / T^{*}$ against $T^{*}$ (dotted lines) are plotted for the different soil types.

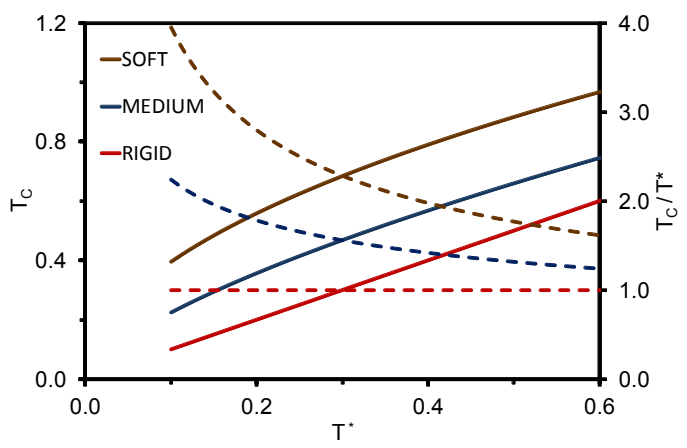

Figure 4: $\quad T_{C}$ (continuous) and $T_{C} T^{*}$ (dotted) versus $T^{*}$ for different soil types.

It is apparent that local effects can determine very large variations of the soil motion. These could be much higher than the uncertainties in the evaluation of the base hazard on rigid soil. Generally speaking, the uncertainties in evaluating the ground motion prediction in PSHA are represented by its standard deviation and, e.g., for short distance to the source one should account for up to 2 or 3 standard deviation [5]. This consideration becomes more important for existing building, for which a reduced seismic action is accepted as specified later.

\section{Some paradoxes in the design codes}

\subsection{The working life time}

The return period $T_{R}$ to consider in the design is related to the reference life $V_{R}$ of the structure by means of assigned relationships. According to the Italian code, for example, for the ultimate limit state $\left(\mathrm{T}_{\mathrm{R}}=\mathrm{V}_{\mathrm{R}} /\left(-\ln \left(1-\mathrm{P}_{\mathrm{R}}\right)\right.\right.$ with $\left.\mathrm{P}_{\mathrm{R}}=0.1\right)$ it is: $T_{R} \approx 9.5 \cdot V_{R}$. It is worth reminding that the reference life $V_{R}$ depends on the design working life $\mathrm{V}_{\mathrm{N}}$ and its importance, measured by means of a use factor, which ranges from 1 to 2 (relative to ordinary and strategic structures, respectively). So it is possible designing two buildings with $V_{R}=100$ years, but having, for example, $V_{N}=50$ years (strategic building $A$ ) and $V_{N}=100$ years 
(ordinary building B), respectively. In practice the two buildings have the same seismic capacity but different design working life and importance. So building B could be used as strategic building for the first 50 years of its life and then declassed to normal building for the next 50 years. On the other hand building A could be used as strategic one for 50 years and then continue its life as normal building at least 50 years more. The paradox is very apparent. Safety should not depend on the design working life of the structure, which is an architectural concept, related to the suitability of the structure in satisfying its intended use.

What is our suggestion? The earthquake relative to $P_{R}=10 \%$ in 50 years seems to be sufficient for ordinary buildings, as demonstrated by past constructions. It is worth reminding that traditional buildings are usually designed accounting for a certain capacity of the structure to dissipate energy during the earthquake. This implies that under the design earthquake the structure will not collapse but can suffer damage. For a well designed building, this happens also in case of event even stronger that the design one. For strategic structures the minimum value $\mathrm{P}_{\mathrm{R}}=2 \%$ should be considered or, in alternative, the maximum credible earthquake (MCE), which is the event of highest intensity expected in the area. An intermediate value $P_{R}=5 \%$ could be considered for structure of particular relevance, such as schools, but it would be wise designing these with $\mathrm{P}_{\mathrm{R}}=2 \%$ in order to use them as emergency or strategic structures in case of earthquake.

\subsection{The behaviour factor}

Realizing structures able to support the effective seismic actions in the elastic range, i.e., without damage, is not suitable both for economic and architectural reasons. Therefore, in the design spectrum the elastic spectral amplitudes can be reduced by means of the behavior factor in order to account for the capacity of the structure to dissipate energy during the earthquake. The behavior factor depends on the structural type and on the characteristics of the structural details. This appears certainly correct for high seismicity areas (HSA) but technical codes allow using the same behavior factors, for each structural type, also in medium and low seismicity areas (MSA and LSA, respectively). Actually designing without any reduction of the elastic acceleration values would be possible in LSA, also from economical and architectural points of view.

What is our suggestion? A maximum design spectral value $\mathrm{S}_{\mathrm{d} \text {,max }}$ should be defined, based on economic and architectural considerations (Figure 5). If the elastic spectral amplitude is lower than $S_{d, \max }$, then the elastic value is assumed as design value. If not, $\mathrm{S}_{\mathrm{d} \text {,max }}$ should be assumed as design spectral value and a behavior factor is considered to account for the capacity of the structure to dissipate energy. This should depend on the elastic spectral amplitude, i.e., on the seismic hazard at the site and on the fundamental period of vibration of the structure. Obviously, $\mathrm{S}_{\mathrm{d}, \max }$ is a function of the structural type. 


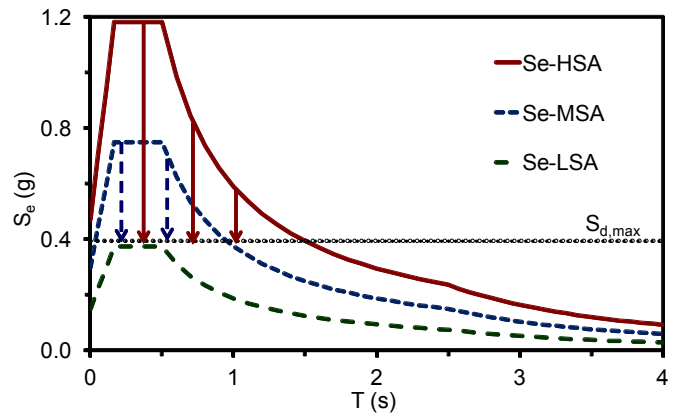

Figure 5: Ductility demand variable with the spectral amplitude.

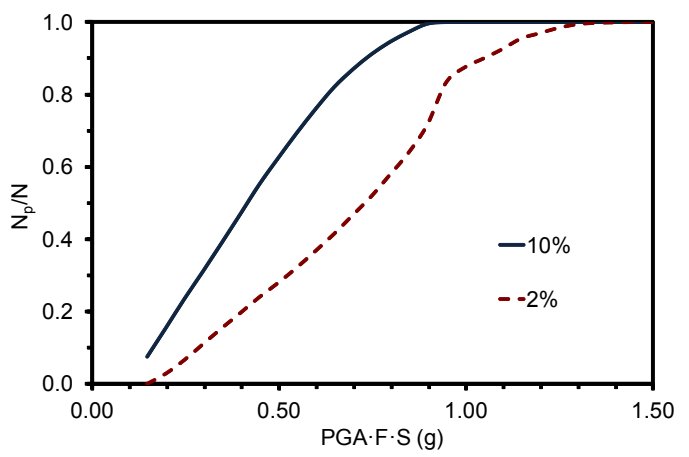

Figure 6: Distribution functions of $\mathrm{PGA} \cdot \mathrm{F} \cdot \mathrm{S}$, for $P_{R}=10 \%$ and $P_{R}=2 \%$ in 50 years.

In Figure 6 for each maximum value of the spectrum $\mathrm{PGA} \cdot \mathrm{F}$ the percentage of the Italian territory in which this is not exceeded is plotted, in the hypothesis of uniform distribution of soil types For example, if $\mathrm{PGA} \cdot \mathrm{F} \cdot \mathrm{S}=0.4 \mathrm{~g}$ is assumed as maximum design value, the elastic design would be possible in almost $50 \%$ of the Italian territory at $\mathrm{P}_{\mathrm{R}}=10 \%$.

\subsection{The very low seismicity areas}

The very low seismicity areas are those in which codes allow not to adopt the design details required for anti-seismic structures. Usually codes refer to the value of the maximum acceleration on rigid soil or at surface, and proposed values are $\mathrm{PGA}=0.05 \mathrm{~g}$ and $\mathrm{PGA} \cdot \mathrm{S}=0.075 \mathrm{~g}$, respectively. The second is influenced also by the foundation laying but both of them do not account for the effects on the structures. In this optic the parameter PGA.F.S is better representative. Starting from the previous values, the very low seismicity areas could be defined by $\mathrm{PGA} \cdot \mathrm{F} \cdot \mathrm{S} \leq 0.20 \mathrm{~g}$. It is worth pointing out that a suitable definition should refer to the actual spectral amplitude $\mathrm{S}_{\mathrm{e}}(\mathrm{T}, \xi)$ at the period $\mathrm{T}$ of the structure and for its damping $\xi$. In that way, the definition of very low seismicity area will be substituted by the other of "structures less sensitive to the 
earthquake at the site", which is more suitable and in accordance with what already said about the use of the behavior factor. In some way this statement seems to indicate the need to replace analysis based on seismic hazard with those based on seismic risk evaluation and is also suitable for base isolated structures.

\section{Seismic retrofit of existing buildings}

The complete seismic rehabilitation of existing buildings is quite hard, both from the economical and technical point of view. Therefore a partial rehabilitation is usually allowed, i.e., a seismic improving, which is pursued by assuming a reduced seismic action (usually ranging from 60 to $80 \%$ of the demand for new buildings). So seismic improving consists of considering a design earthquake less severe than the actual one, and so a higher value of $P_{R}$. This makes the evaluation of the seismic hazard less important. An error in the hazard evaluation is completely covered by the choice of the seismic improving percentage. Often, in case of historical buildings, the type of intervention is chosen, which respect the historical value, and then the capacity is evaluated.

It is worth pointing out that also buildings that have suffered few damages during seismic events should be retrofitted or improved. If the seismic retrofit is done by means of base isolation, the total rehabilitation should be pursued. In fact, when the structural safety is entrusted to a limited number of devices, a higher safety degree should be required for them. So these should be designed with reference to a higher seismic action, i.e., to a lower value of $P_{R}[6]$.

Among the existing buildings a special mention is due to cultural heritage structures, for which a suitable equilibrium between two opposite requirements should be pursued, i.e., a partial seismic improvement should be obtained, but the original monumental characteristics, identity and historical value must be preserved. In these cases the new anti-seismic technologies can be very useful $[7,8]$.

\section{Conclusions}

"I mentioned the technicisms because in some aspects the tendency to proliferation of codes can be connected to it. Obviously, the rules have noble motives, i.e., the structural safety and lending consistency and safety in a fragmented and sometimes confusing frame. But a high number of rules involve many drawbacks: the impoverishment of autonomy and creativity, the difficulty to discern what is really important, the feeling of being relieved of responsibilities .... Among these consequences, one of the most dangerous is the attenuation of the sense of responsibility, while this is one of the fundamental human rights, whose violation flattens life and, through the settlement of a super organized society, strengthen the establishment of a technocratic system that can become, as Konrad Lorenz said, the tyrant of human society, because the technocracy takes advantage of the scientific information heritage that the individual can know only in a small part" [9]. The words of Pozzati are still present and agree with the famous motto "the regulations for design are to 
regulate those who cannot design". This motto has several meanings, among these it underlines that the art of well designing is much more than just following the prescriptions of the codes. In fact, the respect of the rules given by the codes cannot guarantee the good performance of the structure. This consideration leads to a different thinking about the seismic design rules.

\section{References}

[1] Bazzurro P., Alexander D., Clemente P., Comerio M., De Sortis A., Filippou F., Goretti A., Jorjani M., Mollaioli F., Mosalam K., Price H.J., Court C.P., Schotanus M., Stewart J., Learning from Earthquakes. The Mw 6.3 Abruzzo, Italy, Earthquake of April 6, 2009. EERI Special Earth. Report, 2009.

[2] Çelebi M., Bazzurro P., Chiaraluce L., Clemente P., Decanini L., De Sortis A., Ellsworth W., Gorini A., Kalkan E., Marcucci S., Milana G., Mollaioli F., Olivieri M., Paolucci R., Rinaldis D., Rovelli A., Sabetta F. and Stephens C., "Recorded Motions of the Mw6.3 April 6, 2009 L'Aquila (Italy) Earthquake and Implications for Building Structural Damage: A Review”. Earthquake Spectra, EERI, 26(3), pp. 651-684, 2010.

[3] Masi A., Prime riflessioni sull'esperienza del terremoto in Abruzzo. Assemblea Nazionale dei Presidenti degli Ordini degli Ingegneri Roma 9 maggio 2009, http://www.tuttoingegnere.it/, 2009.

[4] Clemente P., "Tohoku Earthquake of March 11 ${ }^{\text {th }}, 2011$ ". Contribution to Italy in Japan 2011. Science, Technology and Innovation. ENEA, http://www.enea.it/it/internazionali/enea-in-japan-2011/, 2011.

[5] Bommer J. J., Abrahmson N. A., "Why Do Modern Probabilistic SeismicHazard Analyses Often Lead to Increased Hazard Estimates?", Bull. Seism. Soc. of America, 96(6), 1967-1977, 2006.

[6] Clemente P., Buffarini G., "Base isolation: design and optimization criteria". Seis. Isol. and Prot. Sys., Math. Science Publisher, 1(1), pp. 17 40, 2010.

[7] Clemente P., Buffarini G. (2009). "Dynamic Response of Buildings of the Cultural Heritage". Encyclopedia of Structural Health Monitoring, eds. Boller C., Chang F.K. and Fujino Y., John Wiley \& Sons Ltd, Chichester, UK, pp. 2243-2252.

[8] Clemente P., De Stefano A., "Application of seismic isolation in the retrofit of historical buildings". Earthquake Resistant Engineering Structures (Proc., ERES 2011, Sept. 7-9, Chianciano, Italy), eds. Brebbia C.A. \& Maugeri M., WIT Trans. on The Built Environment, 120, pp. 41-52, 2011.

[9] Pozzati P. (1993). "Proliferation of regulations and technicality," AICAP News attached to Industria italiana del cemento, No. 3 (in Italian). 